\title{
BRINQUEDO TERAPÊUTICO BOLA DAS SENSAÇÕES: UM RELATO
} DE EXPERIÊNCIA

BOLA DAS SENSAÇÕES: UM RELATO

THERAPEUTIC TOY SENSATION BALL: AN EXPERIENCE REPORT

SENSATION BALL: A REPORT

\author{
Mariana Coelho Rodrigues ${ }^{1}$ \\ Dievilin Demenjon de Carvalho ${ }^{2}$ \\ Marlise Lima Brandão ${ }^{3}$ \\ Patrícia da Silva Gariba
}

\begin{abstract}
RESUMO: Objetivou-se relatar a utilização do brinquedo terapêutico - Bola das Sensações - como uma prática de enfermagem em crianças hospitalizadas. Trata-se de um relato de experiência de duas acadêmicas de enfermagem. A vivência ocorreu em agosto de 2018, em um hospital público de grande porte na Região Metropolitana de Curitiba - PR, durante as práticas de campo na disciplina Saúde da Criança. Com o propósito de facilitar a interação do profissional de enfermagem com o paciente, possibilitando à criança momentos de descontração durante o processo saúde-doença, assim como diminuir o grau de estranheza do infante que se encontrava em um lugar com pessoas desconhecidas, foi criado um brinquedo terapêutico denominado Bola das Sensações. A Bola das Sensações foi utilizada com quatro crianças e foi possível observar efeitos benéficos aos pacientes infantis hospitalizados, mas é importante demonstrar que a bola não é mágica, ela necessita que um profissional utilize-a com a criança e demonstre sua funcionalidade, este profissional precisa ter empatia pela criança reconhecendo suas necessidades, criatividade, medos e angústias. A experiência vivenciada pelas acadêmicas foi de grande relevância para a formação, uma vez que possibilitou o reconhecimento de informações valiosas relacionadas às crianças, assim como a oportunidade de desenvolver um brinquedo terapêutico - a Bola das Sensações.
\end{abstract}

Palavras-chave: Jogos e brinquedos. Enfermagem Pediátrica. Cuidados de Enfermagem.

ABSTRACT: The objective of this paper is to report the use of the therapeutic toy - Ball of Sensations - as a nursing practice tool in hospitalized children. This is an experience report by two nursing students. The experience occurred in August 2018, in a large public hospital in the metropolitan region of Curitiba - PR, during the field practices in the Child Health course. As a result, the Ball of Sensations was elaborated, facilitating the interaction of the nursing professional with the patient, allowing the child moments of relaxation during the health-disease process, as well as reducing the degree of the strangeness of the infant who was in a place with unknown people, a situation in which it is necessary to consider child's particularities and needs. The Ball of Sensations has been used with four children, and the beneficial effects could be seen in the hospitalized child patients, but it is important to demonstrate that the ball is not magic, it requires a professional to use it with the child and to demonstrate its functionality, this professional needs to have empathy for the child, recognizing their needs, creativity, fears, and anxieties. The experience lived by the students demonstrated great relevance for the nursing formation, since it allowed the recognition of valuable information related to the children, as well as the opportunity to develop a therapeutic toy - the Ball of Sensations.

Keywords: Games and toys. Pediatric nursing. Nursing care.

\footnotetext{
${ }^{1}$ Enfermeira. Pós graduanda em Home Care. E-mail: mari_gtr@hotmail.com.

2 Enfermeira.

${ }^{3}$ Enfermeira. Mestre em Enfermagem. Docente do Curso de Enfermagem do Centro Universitário Autônomo do Brasil - UNIBRASIL.

${ }^{4}$ Enfermeira. Especialista em Estomaterapia.
} 
INTRODUÇÃO

Os cuidados de enfermagem com crianças demandam, além da empatia e proximidade necessárias, algumas estratégias que visam um melhor entendimento das queixas da criança e de como ela está lidando com a doença em seu estado de fragilidade ${ }^{(1)}$. O modo como o profissional da saúde trata e acolhe a criança e os familiares é muito relevante para que eles se sintam seguros no processo saúde-doença ${ }^{(2)}$.

A inserção de práticas como a utilização de brinquedo terapêutico para as crianças pode ser entendida como um passo importante na direção da humanização do atendimento. Percebe-se que para a criança, o brincar é uma atividade muito relevante do ponto de vista físico, social, emocional e mental, deste modo as necessidades de desenvolvimento das crianças hospitalizadas são as mesmas das crianças não hospitalizadas e devem promover o bem-estar ${ }^{(3)}$.

As brincadeiras são uma forma de comunicação da criança com o mundo, pois ajudam no desenvolvimento de habilidades sociais, inclusive a ausência das brincadeiras pode ocasionar distúrbios no comportamento, alterações no sono e atraso no desenvolvimento ${ }^{(3)}$.

O brinquedo terapêutico (BT) não é uma simples brincadeira, mas um brincar estruturado, pois é direcionado por um profissional da saúde para atingir um objetivo específico, o que proporcionará uma aproximação do paciente e possibilitará uma melhor compreensão do mundo sob a ótica da criança ${ }^{(4)}$.

O objetivo do brinquedo terapêutico é promover um alívio da tensão e o bem-estar da criança internada, ele ainda pode ser um meio de comunicação que auxilia a criança a compreender o tratamento, minimizando a ansiedade ${ }^{(5)}$, assim como possibilita que ela se expresse e sinta-se confiante, pois terá a sensação de controle do momento ${ }^{(3)}$, diminuindo a irritação e o estresse provocados pela hospitalização ${ }^{(6)}$.

Partindo dessas premissas é possível compreender a importância do brinquedo terapêutico na assistência de enfermagem às crianças hospitalizadas, pois, ao tentar ver o mundo a partir da visão da criança, o enfermeiro acaba criando a possibilidade de estabelecer vínculos de amizade e afeto com o paciente e com a família ${ }^{(3)}$.

\section{DESENVOLVIMENTO}

Sabe-se que a criança possui diversas maneiras de se expressar, mas ao se encontrar num ambiente diferente e desconhecido, ela pode ter difiuldades para se comunicar, 


\section{Cadernos da Escola de Saúde}

demonstrando-se retraída ou não se expressando de maneira clara. O brinquedo terapêutico constituiu-se numa estratégia de aproximação das crianças em situação de internamento no hospital com os profissionais de saúde ${ }^{(3)}$.

O BT é basicamente um brinquedo normal, mas torna-se terapêtico quando ele promove algum bem-estar para a criança ou é utilizado para promover um diálogo com os profissionais da saúde ${ }^{(7)}$.

Percebe-se que no processo de hospitalização a criança é submetida a diversos procedimentos e isso acaba aumentando a sua vulnerabilidade e pode contribuir para o aparecimento de traumas. Nesse contexto, o brinquedo terapêutico poderia auxiliar em pelo menos quatro funções: a) recreação; b) desenvolvimento sensorial; c) socialização; d) catarse. (1).

No que diz respeito à primeira função, a recreação, pode-se dizer que o brinquedo terapêutico alia prazer e distração para a criança; quanto ao desenvolvimento sensorial, ele estimula o intelectual e a criatividade de maneira natural na criança; na parte da socialização, a atividade com o brinquedo terapêutico permite à criança a vivência de diversos papéis sociais e, consequentemente, a relacionar-se com os demais; por fim, no que diz respeito à catarse, o brinquedo possibilita a dramatização de papéis e conflitos que talvez ela esteja enfrentando, aliviando a provável tensão emocional ${ }^{(1)}$.

O Brinquedo Terapêutico é uma ferramenta fundamental aos profissionais da área da saúde que trabalham em unidades pediátricas, especialmente no preparo da criança para procedimentos invasivos, propiciando maior aceitação e cooperação. Quando ela não é preparada emocionalmente para a hospitalização e para os procedimentos hospitalares, pode apresentar uma série de comportamentos em função do medo do desconhecido, comprometendo suas habilidades para lidar efetivamente com essa experiência ${ }^{(1: 1)}$.

Ainda no que diz respeito ao brinquedo terapêutico, é relevante pontuar que, devido à importância dessa ferramenta, seria importante na formação profissional em enfermagem existir uma matéria destinada a pontuar o lugar do brincar nas vivências hospitalares da criança $^{(8)}$.

Diante disso, levanta-se o seguinte questionamento: Diante de um contexto hospitalar com muitas rotinas que são alheias à realidade das crianças, de que maneira os cuidados em enfermagem poderiam contribuir para o estabelecimento de um canal de comunicação com a criança e práticas mais humanizadoras? 
Compreendendo a relevância do brincar, o enfermeiro pode utilizar-se do BT para auxiliar a criança na convivência neste ambiente hostil e diferente do seu cotidiano familiar ${ }^{(9)}$. Do mesmo modo, o brincar pode dar forças para a criança que se encontra imóvel física e psicologicamente no ambiente hospitalar, levando-a a sentir-se mais preparada para enfrentar os procedimentos médicos ${ }^{(10)}$.

Outra funcionalidade do BT é a construção de um canal de comunicação com a criança na sua própria linguagem, de acordo com sua interpretação do mundo e do que a cerca ${ }^{(11)}$, situação que pode facilitar as atividades do enfermeiro, uma vez que pode favorecer a escolha das intervenções com o paciente infantil ${ }^{(12)}$, visto que é extremamente relevante para o cuidado que se entenda como o indivíduo encara seu processo saúde-doença ${ }^{(13)}$.

O brinquedo terapêutico utilizado e desenvolvido pelas acadêmicas foi a "Bola das Sensações”. A ideia surgiu a partir da necessidade de interagir com a criança hospitalizada a fim de prestar uma assistência de cuidado mais humanizada e focada, tornando as ações dos profissionais de enfermagem mais dinâmicas, passando segurança para a criança e permitindo que expressassem seus sentimentos por meio das figuras impressas na bola.

Nesse contexto, a utilização da "Bola das Sensações" visou estabelecer uma comunicação e construir laços de confiança entre a criança hospitalizada e o profissional de saúde, especificamente os acadêmicos de enfermagem, com a pretensão de promover um cuidado mais adequado da criança e proporcionar um relaxamento físico, social e mental, consequentemente influenciando o tratamento.

Um problema identificado no ambiente é a inexistência de uma comunicação adequada com a faixa etária do paciente. Muitos profissionais tratam as crianças de igual maneira aos adultos e isso prejudica a interação: uma vez que existem algumas coisas que elas não compreendem, é importante o uso de linguagem própria no tratamento do paciente pediátrico, pois a criança se relaciona com o meio de uma maneira diferente dos adultos e, nesse caso, é preciso perceber qual é a visão de mundo da criança para iniciar o diálogo ${ }^{(7)}$, assim como perceber as limitações na capacidade de compreensão das situações vivenciadas por elas ${ }^{(14)}$.

O brinquedo deve ser utilizado pelo profissional de enfermagem para assistir à criança, compreender suas necessidades ${ }^{(15)}$, preparar o paciente para procedimentos e exames médicos e diminuir a tensão antes e após as intervenções ${ }^{(16)}$, é isso que torna um brinquedo comum em terapêutico ${ }^{(17)}$, desde que usado frequentemente com o objetivo do bem-estar no contexto hospitalar $^{(18)}$. 


\section{Cadernos da Escola de Saúde}

Ainda destacando-se o diálogo, é oportuno enfatizar que nessa construção é preciso estabelecer uma relação de confiança, que pode ser dificultada pelo estado emocional e físico da criança, gerando algumas barreiras na comunicação que devem ser superadas com interações adequadas, como a utilização do brinquedo terapêutico, por exemplo ${ }^{(8)}$.

Desta forma, argumenta-se que os possíveis despreparos dos profissionais inseridos na equipe multidisciplinar muitas vezes são condicionados a atender um número grande de pacientes, com múltiplas idades e problemas, tratando a todos de uma maneira similar. Entretanto, cada paciente possui sua singularidade, sua particularidade e sua subjetividade.

Sendo assim, o objetivo deste estudo é relatar a utilização do brinquedo terapêutico Bola das Sensações - como uma prática de enfermagem em crianças hospitalizadas.

\section{METODOLOGIA}

A experiência vivenciada ocorreu durante as práticas de campo das acadêmicas de enfermagem de uma universidade privada do Sul do Brasil, especificamente durante o sexto período da graduação em enfermagem. Levou-se em consideração a necessidade da criança de brincar, mesmo num ambiente hospitalar. Por isso, percebeu-se que o brinquedo terapêutico, como a bola das sensações, atingiria esse fim.

Para esta prática de campo, havia uma proposta de desenvolver um brinquedo terapêutico, com o qual as acadêmicas deveriam realizar intervenções de enfermagem, sob a supervisão de uma professora.

Para preservar o anonimato das crianças que utilizaram o brinquedo, cada uma delas foi numerada com algarismos arábicos de um a quatro.

O público-alvo foram as crianças atendidas pelas acadêmicas de enfermagem autoras deste estudo. Focou-se na "ala" de pediatria, que consistia na Enfermaria de um hospital localizado na região metropolitana de Curitiba. Desse modo, a utilização do brinquedo terapêutico teve sua abrangência limitada aos atendimentos realizados pelas acadêmicas neste hospital.

A aplicação ocorreu com 04 (quatro) crianças durante todo o período matutino, das 07h30 às $11 \mathrm{~h} 30$. Essas crianças participaram da experiência num período total de 03 (três) dias. A partir da utilização do brinquedo terapêutico foi possível realizar a avaliação dos exames físicos de enfermagem. 
Como se trata de um relato de experiência, a utilização do brinquedo foi explicada para os pais e informada que os dados poderiam ser utilizados em publicação científica, mas nenhum paciente ou familiar foi exposto.

Não há riscos diretos ou indiretos à utilização do brinquedo em crianças hospitalizadas.

$\mathrm{Na}$ parte dos resultados serão expostos os benefícios aos pacientes que realizaram a experiência.

Por fim, os critérios de inclusão na participação do estudo foram as crianças atendidas pelas acadêmicas na enfermaria do hospital supracitado e o critério de exclusão foi as crianças não atendidas pelas acadêmicas.

O roteiro para o exame físico das enfermeiras seguiu as normas do livro Potter e as fichas foram de autoria das docentes responsáveis pela disciplina de estágio. Os dados foram coletados de acordo com a percepção das acadêmicas, com base nos teóricos citados em todo o trabalho.

\section{Origem da Bola das Sensações}

O brincar é um aspecto muito relevante na vida de uma criança, pois pela brincadeira ela acaba desenvolvendo habilidades, criatividade e novos significados às coisas em sua volta a partir do faz-de-conta ${ }^{(1)}$. Um dos instrumentos é o brinquedo terapêutico. Não há uma forma específica de uso ou um único brinquedo, são múltiplas formas de utilização a depender das necessidades e debilidades em que o paciente se encontra ${ }^{(3)}$.

A escolha do brinquedo terapêutico iniciou-se primeiramente com as informações dadas para início das práticas de campo na enfermaria pediátrica, a qual abrangia a faixa etária dos recém-nascidos até os 15 anos de idade.

Após diagnóstico situacional acerca das dificuldades e melhorias para a realidade vivenciada, teve-se a responsabilidade de se desenvolver e aplicar um brinquedo para ambos os sexos e que fosse criativo, funcional e chamativo. Desta forma, criou-se o brinquedo terapêutico dramático, a Bola das Sensações. Tendo como finalidade interagir com a criança no processo saúde-doença e proporcionar bem-estar, físico, social e mental, ele deve ser utilizado diariamente por um período de 15 a 45 minutos, facilitando ao profissional a compreensão das necessidades da criança.

O público alvo para a Bola das Sensações foi selecionado com base no ciclo de desenvolvimento, crianças da segunda a terceira infância, entre 3 a 11 anos. Para que o 


\section{Cadernos da Escola de Saúde}

brinquedo seja eficaz, a criança deve ter as capacidades motoras avançadas, pois o brinquedo necessita da compreensão da criança das faces presentes na bola, isto é, a criança tem que interpretá-las e encaixá-la para expressar corretamente o que está sentindo.

A Bola das sensações pode ser aplicada em qualquer instituição de saúde, hospital, Unidades Básicas de Saúde, Clínicas, Unidades de Pronto Atendimento e outros, onde haja um profissional capacitado para intervir no que for necessário.

\section{RESULTADOS E DISCUSSÃO}

\section{Descrições do Brinquedo Terapêutico}

A bola desenvolvida pelas acadêmicas é constituída de círculo de isopor, com guizo no interior, sobre o qual se aplicou Etil-Vinil-Acetato (EVA), colada com imagens referentes às sensações e recoberto com adesivo vinílico para facilitar a higienização (Figura 1).

Figura 1 - Bola das Sensações

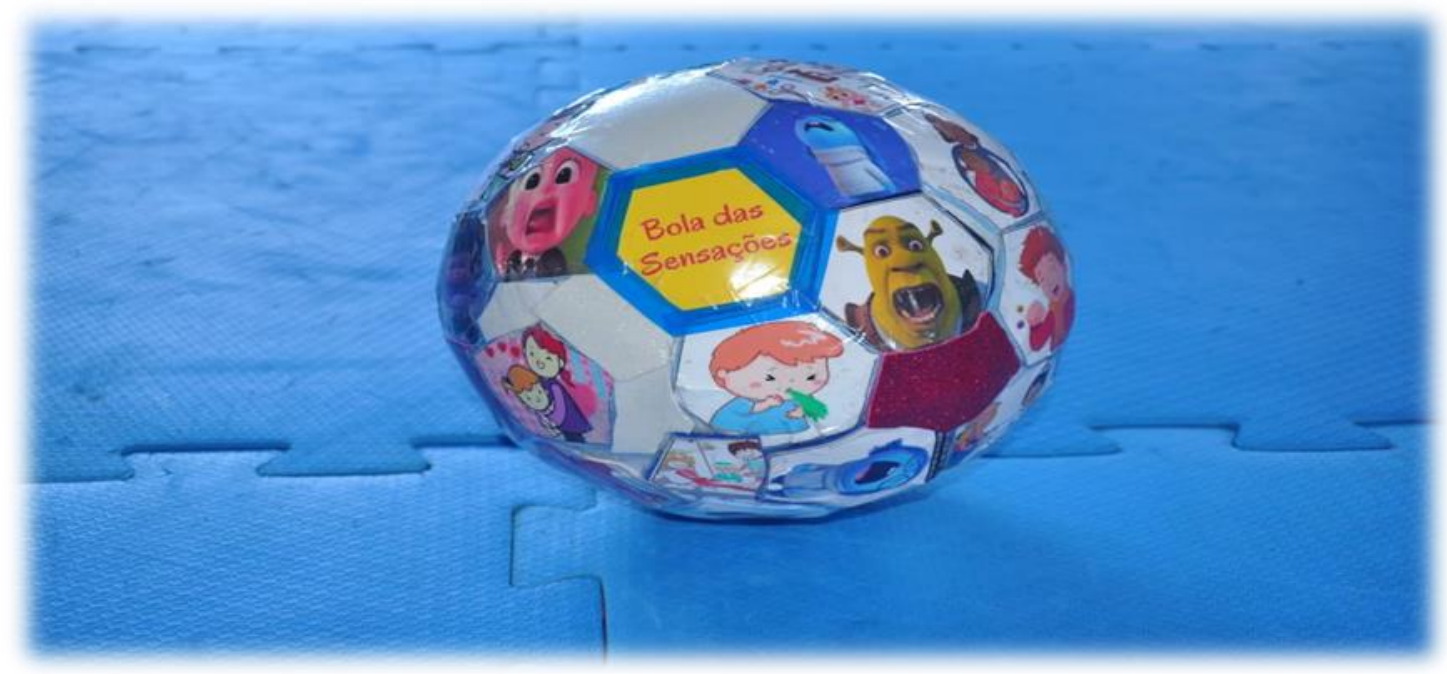

Fonte: As autoras (2019).

A confecção deste brinquedo, inicialmente, pretendeu facilitar a interação do profissional de enfermagem com o paciente, possibilitando à criança se descontrair no seu internamento hospitalar. Além disso, no exame físico do paciente a bola foi utilizada como peça fundamental, pois possibilitou analisar a movimentação dos membros superiores, a força com que a criança segurava a bola, sua capacidade visual, o exame neurológico e auditivo ao perceber o som produzido pela bola ao balançá-la. 
Como seu próprio nome diz, a Bola das Sensações desperta sensações na criança, desde sensações positivas até sensações de lembranças de fatos vivenciados por elas com os familiares. Evidentemente é preciso destacar que a bola não é mágica e por si só não tem utilidade, necessita de alguém para alcançá-la à criança, fazendo valer seu objetivo. Esse alguém é o profissional de saúde que se preocupa e se coloca no lugar da criança reconhecendo suas necessidades, criatividade, medos e angústias.

$\mathrm{Na}$ criação da bola, houve uma preocupação com sua atratividade, som, cores, significado das imagens, relação dos personagens com desenhos animados e filmes atuais, mas principalmente com um público alvo, as crianças.

Essa ferramenta foi atrativa para a criança por ser em um formato comum e colorida, podendo ser utilizada como um objeto de investigação, composto de diversas ilustrações de emoções/sentimentos que a criança pode estar sentindo, passando para os profissionais de saúde informações essenciais para avaliar as medidas de cuidados necessários a serem tomados.

A Bola das Sensações foi utilizada em quatro pacientes pediátricos. As idades dos pacientes variavam de dois a cinco anos (Quadro 1).

As crianças utilizaram a Bola das Sensações em momentos variados, sendo alguns mais extensos e alguns menores, devido às rotinas e procedimentos dinâmicos do hospital que limitava a atuação junto a cada paciente, assim como orientam os autores do livro Enfermagem Pediátrica ${ }^{(18)}$. 
Quadro 01 - Quadro Descritivo da Aplicação da Bola das Sensações

\begin{tabular}{|c|c|c|c|c|c|c|c|}
\hline 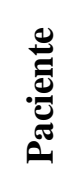 & జ & 胥 & : & $\begin{array}{l}\text { Motivo da } \\
\text { internação }\end{array}$ & $\begin{array}{c}\text { Condições } \\
\text { antes da Bola } \\
\text { das Sensações }\end{array}$ & $\begin{array}{c}\text { Reações da } \\
\text { criança na } \\
\text { visualização da } \\
\text { bola }\end{array}$ & $\begin{array}{l}\text { Condições após } \\
\text { a Bola das } \\
\text { Sensações }\end{array}$ \\
\hline 01 & M & 5 & Não & $\begin{array}{c}\text { Displasia } \\
\text { congênita de } \\
\text { quadril. }\end{array}$ & $\begin{array}{c}\text { Irritação e } \\
\text { choro, } \\
\text { desacompanhada } \\
\text { do responsável. }\end{array}$ & $\begin{array}{c}\text { Curiosidade e } \\
\text { diálogo. } \\
\text { Primeira } \\
\text { interação de } \\
\text { confiança com } \\
\text { um profissional } \\
\text { de saúde. }\end{array}$ & $\begin{array}{l}\text { Coleta de dados: } \\
\text { a) agressão do } \\
\text { pai; b) falta da } \\
\text { mãe (falecida); } \\
\text { c) estresse } \\
\text { devido à } \\
\text { dificuldade de } \\
\text { locomoção. }\end{array}$ \\
\hline 02 & $\mathrm{~F}$ & 3 & Sim & $\begin{array}{l}\text { Fratura de fêmur } \\
\text { bilateral. }\end{array}$ & Choro e dor. & $\begin{array}{c}\text { Cessação do } \\
\text { choro. } \\
\text { Diálogo e } \\
\text { pedido para } \\
\text { manuseá-la. }\end{array}$ & $\begin{array}{c}\text { Tranquilidade, } \\
\text { interação, } \\
\text { comunicação e } \\
\text { reconhecimento } \\
\text { dos } \\
\text { personagens. } \\
\text { Relatou } \\
\text { situações de } \\
\text { briga entre seu } \\
\text { pai e ela. }\end{array}$ \\
\hline 03 & $\mathrm{~F}$ & 6 & Sim & Amigdalectomia. & $\begin{array}{l}\text { Desconfiança, } \\
\text { retração. }\end{array}$ & $\begin{array}{c}\text { Curiosidade, } \\
\text { alegria, } \\
\text { comunicação e } \\
\text { pedido de } \\
\text { manuseio. }\end{array}$ & $\begin{array}{l}\text { Colaboração no } \\
\text { exame físico, } \\
\text { procedimentos e } \\
\text { alimentação. } \\
\text { Tranquilidade e } \\
\text { vínculo de } \\
\text { confiança }\end{array}$ \\
\hline 04 & $\mathrm{~F}$ & 2 & Sim & $\begin{array}{c}\text { Cardiopatia e } \\
\text { Síndrome de } \\
\text { Down. }\end{array}$ & $\begin{array}{l}\text { Agitação e } \\
\text { choro. }\end{array}$ & $\begin{array}{l}\text { Cessação do } \\
\text { choro. }\end{array}$ & $\begin{array}{l}\text { Entretida e } \\
\text { calma. } \\
\text { Realização do } \\
\text { curativo. }\end{array}$ \\
\hline
\end{tabular}

Fonte: As Autoras (2019).

Feitas essas considerações, de maneira quase unânime, percebeu-se que o brinquedo terapêutico produziu alguns efeitos benéficos no tratamento das crianças. Inicialmente o principal benefício da utilização deste instrumento foi o um distrator que permitiu às crianças se acalmarem. Esta, devido ao ambiente alheio a sua rotina, poderia estar arredia ou deslocada e, por isso, poderia chorar. Mas com a introdução da Bola das Sensações foi possível acalmar as crianças a partir de uma brincadeira direcionada.

Deste modo, percebe-se que a utilização da Bola das Sensações confirmou o apontado por outros estudos ${ }^{(17)}$ remetendo que o brinquedo quando utilizado para o bem-estar da 
criança torna-se terapêutico, deixando a criança mais preparada para o enfrentamento dos procedimentos médicos.

A Bola das Sensações proporcionou a criação de um vínculo e confiança com a criança, criando um canal de comunicação sem barreiras, demonstrando a importância da alimentação e das intervenções as quais as crianças eram submetidas, assim como possibilitou que alguns pacientes pediátricos expusessem questões particulares alheias ao tratamento, que afetavam o seu estado emocional, como por exemplo, a agressão paterna e a rigidez dos pais, permitindo a compreensão da visão de mundo do infante, tal como aponta estudo desenvolvido em São Paulo ${ }^{(20)}$.

No que concerne os resultados de movimento, força, audição e visão dos pacientes que participaram da pesquisa, notou-se que todos estavam dentro do padrão de normalidade.

Nesse contexto, insere-se a preocupação do estudo publicado em São Paulo ${ }^{(8)}$ que apontou para a necessidade da compreensão da importância do BT e da inclusão dessa matéria na formação profissional.

\section{CONSIDERAÇÕES FINAIS}

Conforme se verificou, a literatura tem apontado para a importância da utilização de instrumentos auxiliares na construção de laços e pontos com os pacientes em situação de internamento, entre eles o brinquedo terapêutico.

Não há uma forma específica ou um único brinquedo, mas existem múltiplas formas de utilização a depender das necessidades e debilidades do paciente. Pode ser utilizado em qualquer faixa etária, mas é mais comumente utilizado em pacientes pediátricos ou em idosos.

Neste relato de experiência verificou-se que a Bola das Sensações, enquanto brinquedo terapêutico: foi um importante instrumento de construção de um cenário menos hostil para a criança; auxiliou na construção de um canal de confiança entre profissional e paciente; criou um canal de comunicação, onde a criança pôde expor questões até mesmo alheias ao seu tratamento, mas que afetava ou influenciava seu estado clínico.

Ao propor um novo cenário para criança por meio da Bola das Sensações, as acadêmicas puderam estimular a criação de um olhar mais ameno para as situações de intervenção vivenciadas, tendo em vista que a criança cria um mundo imaginário em torno das brincadeiras e a partir dele representa alguns fatos da realidade, conseguindo lidar de maneira mais significativa com situações complexas. 


\section{Cadernos da Escola de Saúde}

As dificuldades e/ou limitações deste estudo ficaram condicionadas à sistemática do hospital, mas estas foram minimizadas a partir da aplicação da Bola das Sensações e, consequentemente, do estabelecimento de uma relação de confiança com a criança que se sentiu à vontade para externar suas sensações e seus sentimentos às acadêmicas de enfermagem.

\section{REFERÊNCIAS}

${ }^{(1)}$ Kiche MT, Almeida FA. Brinquedo terapêutico: estratégia de alívio da dor e tensão durante o curativo cirúrgico em crianças. Acta Paulista de Enfermagem. 2009; 22(2): 125-130.

(2) Marques DKA, Silva KLB, Cruz DS, Souza IVB. Benefícios da Aplicação do brinquedo terapêutico: visão dos enfermeiros de um hospital infantil. Arq. Ciênc. Saúde. 2015; 22(3): 64-68.

(3) Oliveira CS, Maia EBS, Borba RIH, Ribeiro CA. Brinquedo Terapêutico na assistência à criança: percepção de enfermeiros das unidades pediátricas de um hospital universitário. Rev. Soc. Brasileira de Enfermagem Pediátrica. 2015; 15(1):21-30.

(4) Veiga MAB, Sousa MC, Pereira RS. Enfermagem e o brinquedo terapêutico: vantagens do uso e dificuldades. Rev. Eletrôn. Atualiza Saúde. 2016; 3(3):60-66.

(5) Simões Júnior JS, Costa RMA. A construção do brinquedo terapêutico: subsídios para cuidar em enfermagem pediátrica. Revista Pesquisa, Cuidado e Fundamental [Online]. 2010 [citado 2019 out. 21]; 2(supl.2): 728-731.

(6) Green CS. Entendendo as necessidades das crianças através do brinquedo terapêutico. Nursing (São Paulo). 1974; 04 (10), 31-2.

(7) Souza LPS, Silva CC, Brito JCA, Santos APO, Fonseca ADG, Lopes JR. O Brinquedo Terapêutico e o lúdico na visão da equipe de enfermagem. J Health Sci Inst. 2012; 30(4):3548.

${ }^{(8)}$ Leite TM, Shimo AK. Uso do brinquedo no hospital: o que os enfermeiros brasileiros estão estudando? Rev Esc Enferm USP. 2008; 42(2):389-95.

(9) Junqueira MF. A mãe, seu filho hospitalizado e o brincar: um relato de experiência. Estud Psicol (Natal). 2003; 8(1): 193-197.

(10) Maria EB, Guimarães RN, Ribeiro CA. O significado da medicação intratecal para a criança pré-escolar: expresso em sua brincadeira. Rev Paul Enferm. 2003; 22 (3): 268-76.

(11) Trezza EM. Função dos jogos e brinquedo na vida da criança. J Pediatr (Rio de Janeiro). 1977; 42 (6): 55-8. 
${ }^{(12)}$ Furtado MC, Lima RA. Brincar no hospital: subsídios para o cuidado de enfermagem. Rev Esc Enferm USP. 1999; 33(4): 364-9.

(13) Medeiros G, Matsumoto S, Ribeiro CA, Borba RI. Brinquedo terapêutico no prepare da criança para punção venosa em Pronto Socorro. Acta Paul Enferm. 2009; 22 (Edição Especial): 909-15.

(14) Pinheiro MCD, Lopes GT. A influência do brinquedo na humanização da assistência de enfermagem à criança hospitalizada. Rev Bras Enferm. 1993; 46 (2): 117-31.

${ }^{(15)}$ Ribeiro CA. Crescendo com a presença protetora da mãe: a criança enfrentando o mistério e o terror da hospitalização. [tese] São Paulo (SP): Escola de Enfermagem da USP; 1999.

(16) Santos LMCN, Borba RIH, Sabatés AL. A importância do preparo da criança pré-escolar para injeção intramuscular com o uso do brinquedo. Acta Paul Enferm, vol. 13, ano, p. 52-58, 2000.

(17) Huerta EDPN. Aprendendo a preparar a criança para enfrentar situações difíceis e/ou desconhecidas. Rev Esc Enferm USP. 1993; 17 (1): 27-32.

(18) Ribeiro CA, Borba RI. O preparo da criança e do adolescente para procedimentos hospitalares. In: Almeida FA, Sabatés AL. Enfermagem pediátrica: a criança, o adolescente e sua família no hospital. São Paulo: Manole; 2008.

(19) Estrela MT. Investigação, Reflexão, Acção e Formação de Professores. Porto: Porto Editor, 1999.

(20) Melo LL, Valle ER. Brinquedoteca hospitalar. In: Almeida FA, Sabatés AL. Enfermagem pediátrica: a criança, o adolescente e sua família no hospital. São Paulo: Manole; 2008. 